\title{
AVALIAÇÃO DA COMPREENSÃO DOS ÍCONES UTILIZADOS NA PLATAFORMA DE EDUCAÇÃO A DISTÂNCIA DA UNA-SUS/UFMA
}

\author{
Camila Santos de Castro e lima \\ Universidade Federal do Maranhão \\ camilasclima@gmail.com \\ Bruno Serviliano Santos Farias \\ Universidade Federal do Maranhão \\ brunoserviliano@gmail.com
}

Resumo: O presente trabalho tem como objetivo avaliar o grau de compreensão dos ícones utilizados na plataforma on-line de educação a distância da UNA-SUS/UFMA. Foi realizada a avaliação dos ícones presentes nessa interface gráfica, utilizando como diretriz a metodologia de avaliação da compreensão de símbolos gráficos, para tal foi selecionado o teste de compreensão. Foi aplicado um questionário on-line para o levantamento de informações sobre o perfil e experiência dos usuários, seguido do teste de compreensão. Como resultado, a maior parte dos ícones não foi bem compreendida, o que mostra a necessidade de um projeto de redesign. Foram percebidos também pontos importantes para a compreensão de ícones por parte dos usuários, como por exemplo, levar em consideração fatores culturais, bem como a criação de um inventário de signos compondo um sistema visual, o uso de rótulos textuais, entre outros.

Palavras-chave: compreensão, educação a distância, símbolos gráficos.

Abstract: This study reports a research to evaluate the degree of icons understanding that is used in the UNA-SUS/UFMA's distant education online platform. The icons that are in this graphic interface was evaluate using as guide the assessment methodology of understanding of graphic symbols. An on-line questionnaire was used to collect information about users profiles and experience and the comprehension test was applied after. As result most of the icons was not well understood and need a redesign project. Also was perceived relevant points to icon understanding by users, for example, take into cultural background, creation of an inventory of signs to compose a visual system and the use of text labels. icons by the students as well as the need for a redesign project.

Key-words: comprehension, distant education, graphic symbols. 


\section{INTRODUÇÃO}

Os projetos de sistemas pictóricos foram de grande importância para o desenvolvimento dos ícones. Projetos como o do metrô de Londres, o ISOTYPE e os Blissymbols definiram diretrizes, como a simplificação e a sistematização, que são utilizadas até os dias atuais e mostram que os ícones presentes em qualquer interface são essenciais para a comunicação e interferem diretamente na qualidade da interação e do sistema de comunicação (CARDOSO et al. 2014).

Com o desenvolvimento e popularização dos recursos tecnológicos computadores, smartphones, tablets e a internet - diversas áreas da sociedade se apropriaram desses avanços, como a educação a distância (EaD). Entende-se tal modalidade de ensino como a metodologia que permite aos alunos a interação com professores, tutores e instituição em tempo e local físico diferente, através de algum tipo de tecnologia (MOORE e KEARSLEY, 2007).

Para que o aluno tenha acesso ao material de ensino, interaja com os tutores e outros alunos, a EaD faz uso do recurso de Ambientes Virtuais de Aprendizagem (AVAs), que se fazem presentes em grande parte dos cursos ofertados atualmente. $O$ AVA da UNA-SUS/UFMA possui diversos recursos e utiliza-se de ícones para a navegação e organização dos conteúdos.

De qualquer modo, é importante que tais ícones possam ser compreendidos de forma efetiva pelos usuários. Vários estudos têm como tema a avaliação de ícones, como por exemplo, estudos desenvolvidos por Eliana Formiga, em seu livro Símbolos gráficos: métodos de avaliação de compreensão (2011), seu estudo, em parceria com Anamaria de Moraes: Comparação de eficiência de métodos de avaliação de usabilidade pelo método binário (2012), o estudo desenvolvido por Cardoso et.al, Avaliação de ícones para interface de um sistema médico on-line (2014), entre outros. Dentre os principais métodos de avaliação, o teste de compreensão, que busca mostrar de maneira objetiva o grau de compreensão de um ícone, é um dos métodos mais eficazes para esta abordagem.

Nesse sentido o presente artigo tem como objetivo: avaliar o grau de compreensão dos ícones em um sistema interativo virtual. Será abordado a aplicação do teste de compreensão para avaliar os elementos pictóricos utilizados na plataforma de ensino à distância, ou ambiente virtual de aprendizagem, da UNA-SUS/UFMA, com o objetivo de realizar o levantamento de informações para um futuro projeto de redesign.

\section{DESENVOLVIMENTO}

Ícone, segundo Cardoso et al. (2013), etimologicamente significa imagem, e vem se tornando polissêmica com o transcurso do tempo. Ou seja, é um termo que adquiriu diversos significados.

A utilização de metáforas visuais e as associações como base para comunicação foi crucial, possibilitando a compreensão de conceitos abstratos e transpondo a linguagem computacional para uma linguagem comum às pessoas (CARDOSO et al., 2014). CARDOSO et al (2014, p. 71) aprofunda a questão ao afirmar que o ícone pode transcender a barreira da linguagem e representar significados de uma forma sintetizada e condensada. Para essa comunicação entre o usuário e a interface gráfica atinja seus objetivos, faz-se necessário que os ícones sejam projetados de forma eficiente.

No sistema WIMP (janelas, ícones, menus e ponteiros), classificado por Nielsen (1993, apud CARDOSO, 2014), o ícone é parte essencial para que um sistema possa 
funcionar de forma correta, e para que a comunicação entre o usuário e a interface seja completa, sendo assim, devem ser projetados com base em estudos, a fim de desenvolver ícones que facilitem a navegação do usuário dentro de um sistema (CARDOSO, 2014). Logo, é essencial que os ícones sejam projetados com base em estudos e que após seu desenvolvimento, que sejam testados também em relação a sua compreensão pelo usuário.

Considerando a relevância de tema, foram analisados os ícones presentes no Ambiente Virtual de Aprendizagem (AVA) da UNA-SUS/UFMA. No final do ano de 2009, a Universidade Federal do Maranhão aderiu a um projeto do Ministério da Saúde, desenvolvido pela Secretaria de Gestão do Trabalho e da Educação na Saúde - SGTES, a rede Universidade Aberta do SUS (UNA-SUS), para atender às necessidades de capacitação e educação permanente dos profissionais da área da saúde que atuam no Sistema Único de Saúde (SUS).

Atualmente, a UNA-SUS/UFMA, ocupa o segundo lugar na tabela de Recursos disponibilizados no Acervo de Recursos Educacionais em Saúde - ARES por instituição (hierárquica) e coleção até 26/04/2015, com total de 620 objetos e modelos educacionais disponibilizados, ou Recursos Educacionais Abertos (REA). Segundo a definição da Organização das Nações Unidas para a Educação, a Ciência e a Cultura (Unesco) e a Commonwealth of Learning (COL), em 2011, Recursos Educacionais Abertos são:

\footnotetext{
REA são materiais de ensino, aprendizado e pesquisa, em qualquer suporte ou mídia, que estão sob domínio público, ou estão licenciados de maneira aberta, permitindo que sejam utilizados ou adaptados por terceiros. (...) Recursos educacionais abertos podem incluir cursos completos, partes de cursos, módulos, livros didáticos, artigos de pesquisa, vídeos, testes, software, e qualquer outra ferramenta, material ou técnica que possa apoiar o acesso ao conhecimento (UNESCO e COL, 2011 apud SANTANA et al., 2012).
}

A instituição também ocupa o segundo lugar na tabela de itens com downloads e total de downloads, por instituição, nos últimos 90 dias, com 540 itens e 4.532 downloads e ocupa a segunda posição na tabela de 20 itens mais baixados nos últimos 90 dias, com o item ARES/654, Saúde do Adulto I, com 237 downloads.

\subsection{Seleção e identificação dos ícones da UNA-SUS/UFMA}

O AVA da UNA-SUS/UFMA é um ambiente que faz uso da plataforma Moodle e permite que o usuário, após entrar no sistema com login e senha, tenha acesso aos cursos de capacitação e especialização ofertados pela instituição, os objetos de aprendizagem, como o livro on-line, atividades, fórum, vídeos, games, animações, etc., além de poder interagir com o tutor e com outros alunos. Esse sistema pode ser acessado por alunos, tutores e pela própria equipe da instituição. Cada curso é formado por módulos que são formados por unidades, compostas pelo livro on-line, vídeos, animações, games, atividades e fóruns.

O presento projeto foi direcionado para dois ambientes do Ambiente Virtual de Aprendizagem da UNASUS/UFMA: salas virtuais e livro multimídia (on-line). Após realizar o acesso no AVA, e selecionar o curso em que está inscrito, o aluno é direcionado para a página da sala virtual do curso (Figura 1). 

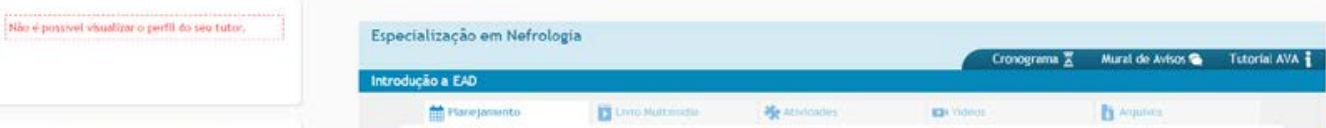

Google play

$\ominus$

Punejanents as modito

\section{REPOSIÇÃO ONLINE!}

CEnTRAL de AIENOIMENTI AD AUUND

Figura 1 - Registro da sala virtual do AVA da UNA-SUS/UFMA.

Fonte: AVA da UNA-SUS/UFMA, 2016.

Ao acessar o AVA e selecionar a unidade, o aluno tem acesso ao livro multimídia ou livro online (Figura 2), onde o conteúdo está disposto junto aos objetos educacionais e midiáticos.

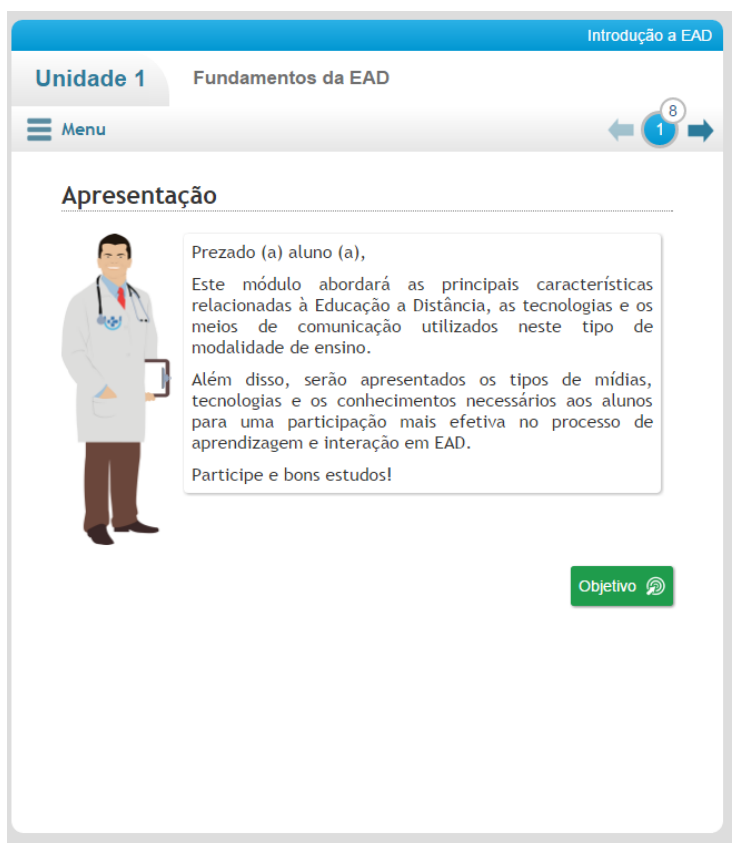

Figura 2 - Registro do livro multimídia da UNA-SUS/UFMA.

Fonte: AVA da UNA-SUS/UFMA, 2016.

Desses dois ambientes virtuais foram destacados os ícones baseado na observação sistemática, com registros de tela para a análise. Foram identificados 24 ícones (Tabela 1), localizados no menu do AVA, no menu do livro-online e no conteúdo do livro on-line, que foram selecionados e suas funções interativas catalogadas com o intuito de avaliar o grau de compreensão e posteriormente aplicar o método de produção. Os ícones selecionados foram: 
Tabela 1 - Inventário dos ícones.

\begin{tabular}{|c|c|c|}
\hline Ícone & Função & Localização \\
\hline 1 & Minicurrículo do professor & Menu AVA \\
\hline 2 & Mural de avisos & Menu AVA \\
\hline 3 & Fórum & Menu AVA \\
\hline 4 & Atividade & Menu AVA \\
\hline 5 & Cronograma & Menu AVA \\
\hline 6 & Planejamento & Menu AVA \\
\hline 7 & Tutorial AVA & Menu AVA \\
\hline 8 & $\begin{array}{l}\text { Livro multimídia } \\
\text { (on-line) }\end{array}$ & Menu AVA \\
\hline 9 & Livro-texto & Menu AVA \\
\hline 10 & Unidades & Menu livro on-line \\
\hline 11 & Home & Menu livro on-line \\
\hline 12 & Imprimir & Menu livro on-line \\
\hline 13 & Tamanho da fonte & Menu livro on-line \\
\hline 14 & Arquivos PDF & Menu livro on-line \\
\hline 15 & Objetivos & Conteúdo do livro on-line \\
\hline 16 & Vídeos & Conteúdo do livro on-line \\
\hline 17 & Referências & Conteúdo do livro on-line \\
\hline 18 & Observação & Conteúdo do livro on-line \\
\hline
\end{tabular}


19

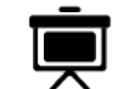

Apresentação

Conteúdo do livro on-line

\section{0}

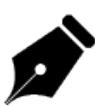

Vamos praticar

Conteúdo do livro on-line

21

22

$$
\bullet
$$

Reflita comigo

Atenção

Caso clínico
Conteúdo do livro on-line

Conteúdo do livro on-line

Conteúdo do livro on-line

Fonte: Elaborado pelo autor, com base na pesquisa realizada, 2016.

\subsection{Métodos aplicados}

Os símbolos gráficos selecionados atuam como auxiliadores do processo de aprendizagem, hierarquizando a informação e organizando o conteúdo. Por isso, vê-se a importância de utilizar metodologias para avaliação dos símbolos gráficos utilizados na plataforma de EAD da UNA-SUS/ UFMA.

Para tal, foi selecionado como métodos de avaliação o teste de compreensão e o método de produção, baseado na explanação de metodologias de avaliação da compreensão de símbolos gráficos presente no livro Símbolos gráficos: métodos de avaliação de compreensão (FORMIGA, 2011), com intuito de avaliar o grau de entendimento correto de cada símbolo, bem como utilizar os ícones que forem aprovados no teste como uma imagem padrão e utilizar os resultados do método de produção para com o levantamento de informações um possível projeto de redesign dos ícones. Nesta etapa serão feitas observações e sugestões não se atendo a questões estéticas ou projetuais de redesign dos ícones.

\subsubsection{Teste de compreensão}

O Teste de compreensão mostra através de dados qualitativos e objetivamente, o grau de entendimento correto de cada símbolo pelo participante (FORMIGA, 2011) e resumidamente, consiste em dispor os ícones seguido de um lugar para que o sujeito possa escrever o significado que the seja mais conveniente (FORMIGA, 2011). Segundo Formiga (2011, p. 45), o contexto de uso pode ser ou não informado. O teste deve ser aplicado com número mínimo de 30 sujeitos (FORMIGA e MORAES, 2012).

A pontuação do teste de compreensão é definida a partir da pontuação estabelecida por Brugger (1994, apud FORMIGA, 2011): 
Quadro 1 - Pontuação de Brugger.

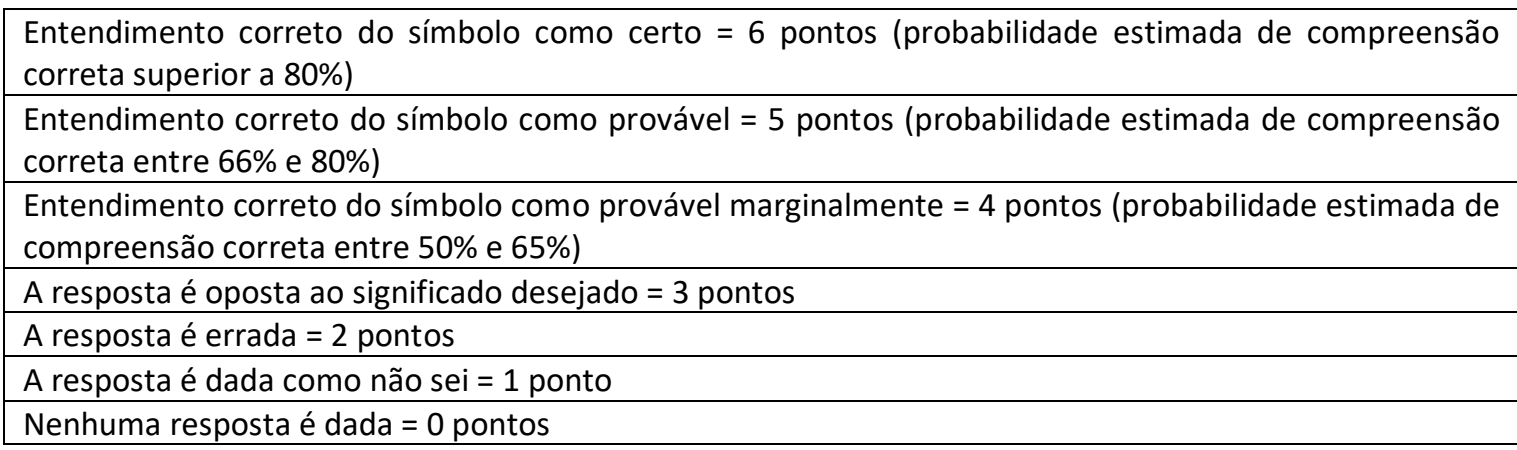

Fonte: Adaptado de: FORMIGA. Símbolos gráficos: métodos de avaliação de compreensão. 2011, p.46.

Para cada símbolo sua avaliação é a média aritmética dada pelos seus pontos alcançados (FORMIGA, 2011, p. 46). Segundo Edwoerthy e Adams (1996, apud FORMIGA, 2011, p. 46), considera-se como taxa de aceitação $66 \%$ para informações públicas e de $85 \%$ para informações específicas e de segurança.

Para avaliar a compreensão dos ícones da UNA-SUS/UFMA foi desenvolvido um questionário on-line, na plataforma Google Docs, dividido em três partes:

- Questionário Perfil: com objetivo de levantar dados relevantes sobre o perfil dos participantes, tais como idade, nacionalidade, grau de escolaridade, área de atuação profissional, entre outras, para o levantamento de fatores que possam influenciar a compreensão dos ícones do sistema;

- Experiência do Usuário: com objetivo de verificar a experiência do usuário com o AVA do curso on-line que já participou anteriormente, levando em consideração quais dificuldades enfrentadas e avaliando a plataforma AVA do curso que participou; e a

- Compreensão dos ícones: com objetivo de verificar a compreensão dos ícones da plataforma da UNA-SUS/UFMA, onde os ícones foram dispostos separadamente, numerados e agrupados de acordo com sua localização (Menu AVA; Menu livro on-line; e Conteúdo do livro online), com um espaço para que o participante pudesse escrever o conceito que lhe foi mais conveniente.

Por tratarem-se de símbolos utilizados para um fim tão específico, no caso a plataforma de ensino à distância da UNA-SUS/UFMA, onde os cursos oferecidos têm como foco profissionais da área da saúde do SUS e/ou estudantes de graduação e pósgraduação na área da saúde, o contexto foi informado.

\subsubsection{Resultados do teste de compreensão}

O teste de compreensão foi realizado com um total de 38 participantes, com:

- $50 \%(n=19)$ dos participantes do gênero feminino;

- $50 \%(n=19)$ masculino,

- $63,9 \%(n=24)$ foram brasileiros

- $36,1 \%(n=14)$ foram cubanos,

- 44,7\%, $(n=17)$ com idade entre 26-35 anos,

- $78,9 \%(n=30)$ da área médica, 
- $47,4 \%(n=18)$ com pós-graduação completa,

- $39,5 \%(n=15)$ com menos de 1 ano de atuação na área.

Dos participantes $42,1 \%(n=16)$ já tiveram experiência com cursos on-line, destes $50 \%(n=8)$ na UNA-SUS/UFMA e $50 \%(n=18)$ em outras instituições de EaD. $37,5 \%(n=6)$ desses 16 participantes tiveram experiência com cursos on-line tiveram dificuldades dentro da plataforma do curso, sendo as principais dificuldades: Rede/conexão (50\%, com $n=3)$; Sistemas de comunicação $(33,3 \%$, com $n=2)$; e Interface gráfica do curso $(33,3 \%$, com $n=2)$. Ainda assim, todos os participantes afirmaram ter conseguido alcançar seus objetivos ao utilizar a plataforma e a maioria $(81,3 \%$, com $n=13$ ) satisfeitos (Figura 3).

\section{PERFIL E EXPERIÊNCIA DOS PARTICIPANTES DO TESTE DE COMPREENSÃO (Total: 38 participantes)}

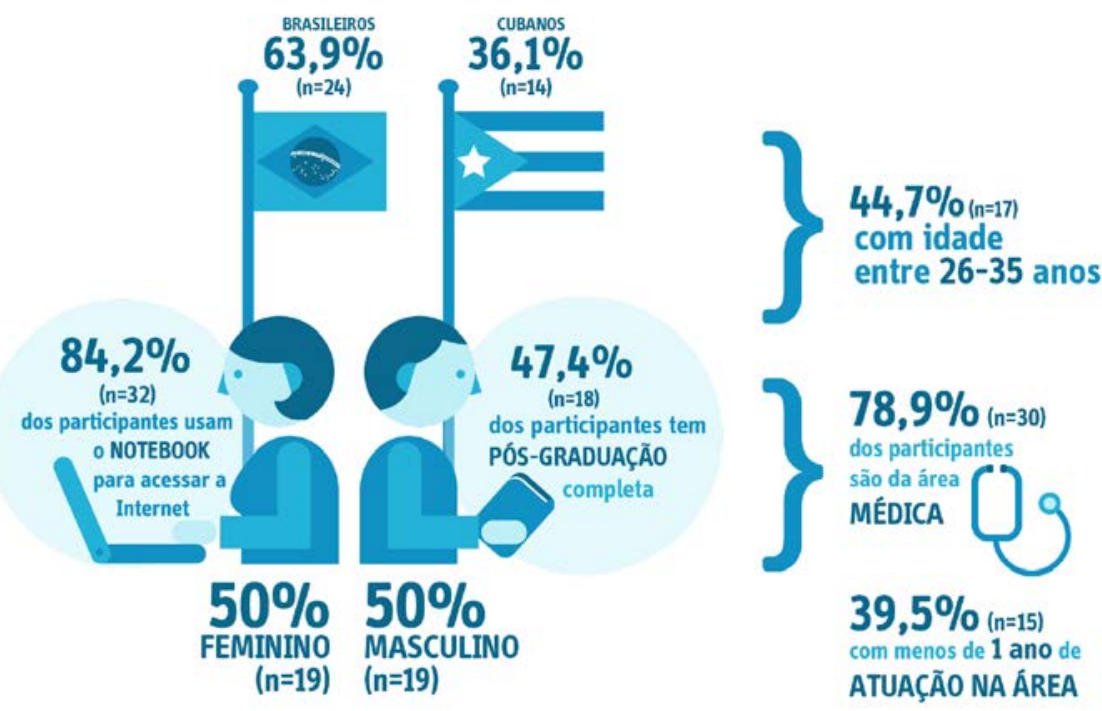

\footnotetext{
@

$42,1 \%(n=16)$ dos participantes já tiveram experiência com cursos on-line.

$50 \%$ na UNA-SUSIUFMA

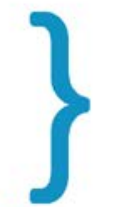

$50 \%$ em OUTRAS INSTTTUIÇões

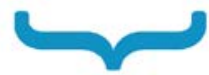

tht 4 MUITO SATISFEITO - $6,3 \%$ ( $\mathrm{n}=1$ )

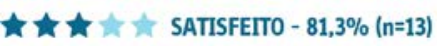

t t 4 INDIFERENTE - $12,5 \%(\mathrm{n}=2)$

\section{$37,5 \%(n=6)$}

dos 16 participantes que já

tiveram experiência com cursos on-line

tiveram DIFICULDADES dentro da plataforma

do curso.

As principais DIFICULDADES foram:

$50 \%$ ( $n=3)$ REDE/CONEXÃO

$33,3 \%$ (n=2) SISTEMAS DE COMUNICAÇÃ̃O

$33,3 \%$ ( $n=2)$ INTERFACE GRÁFICA DO CURSO

Ainda assim, 100\% dos participantes conseguiram ALCANÇAR SEUS OBJETIVOS ao utilizar a plataforma
}

Figura 3 - Resultados do perfil e experiência dos participantes do teste de compreensão. Fonte: Elaborado pelo autor, com base na pesquisa realizada, 2016.

Como resultado do teste de compreensão, foi constatado que os ícones que alcançaram a taxa de aceitação (66\%) foram, em ordem decrescente de percentual, 
apresentados na Tabela 2. Estes ícones foram bem compreendidos pelos participantes do teste de compreensão.

Tabela 2 - Ícones com percentual de compreensão maior que 66\%.

\begin{tabular}{|c|c|c|}
\hline Ícone & Identificação da função & Taxa de Aceitação \\
\hline & Imprimir & $86,8 \%$ \\
\hline & Arquivos PDF & $80,6 \%$ \\
\hline & Vídeos & $73,1 \%$ \\
\hline & Tutorial AVA & $69,1 \%$ \\
\hline mant & Planejamento & $68,6 \%$ \\
\hline $\bar{B}$ & Cronograma & $66,1 \%$ \\
\hline
\end{tabular}

Fonte: Elaborado pelo autor, com base na pesquisa realizada, 2016.

Os ícones que obtiveram percentuais abaixo da taxa de aceitação e acima ou igual a $50 \%$ no teste de compreensão foram, em ordem decrescente de percentual, apresentados na Tabela 3. Esses resultados demonstram que há a necessidade de um redesign para esses ícones, visto que não alcançaram a taxa de aceitação. 
Tabela 3 - Ícones com percentual de compreensão menor que $66 \%$ e acima de $50 \%$.

\begin{tabular}{lll}
\hline Ícone & Identificação da função & Taxa de Aceitação \\
\hline & Tamanho da fonte & $64,8 \%$ \\
\hline & Atenção & $62,1 \%$ \\
\hline & Objetivo & $58,6 \%$ \\
\hline & Livro multimídia (on-line) & $58,6 \%$ \\
\hline & Home & $56 \%$ \\
\hline & Fórum & $55,1 \%$ \\
\hline
\end{tabular}

Fonte: Elaborado pelo autor, com base na pesquisa realizada, 2016.

Os ícones que obtiveram resultados abaixo de $50 \%$ foram apresentados na Tabela 4 em ordem decrescente. 
Tabela 4 - Ícones com percentual de compreensão menor que 50\%.

\begin{tabular}{lll}
\hline & Identificação da função & Taxa de Aceitação \\
\hline & Livro-texto & $49 \%$ \\
\hline & Observação & $49 \%$ \\
\hline & Minicurrículo do professor & $49 \%$ \\
\hline & Apresentação & $38,5 \%$ \\
\hline & Mural de avisos & $36,3 \%$ \\
\hline & Reflita comigo & $16,6 \%$ \\
\hline
\end{tabular}

Fonte: Elaborado pelo autor, com base na pesquisa realizada, 2016.

\section{CONCLUSÃO}

Através do método de compreensão foi possível avaliar objetivamente o grau de compreensão dos ícones presentes no AVA da UNA-SUS/UFMA, com o objetivo de avaliar se esses ícones estavam sendo bem compreendidos pelos usuários da plataforma, através de um questionário on-line, obtendo dados para futuras pesquisas e projeto de redesign.

No total, apenas 6 dos 24 ícones atingiram a taxa de compreensão a cima de $66 \%$. Percebeu-se que esses ícones possuíam uma relação com o objeto real ou um significado já estabelecido (no caso do ícone Tutorial AVA).

Nove ícones tiveram uma taxa de aceitação entre 50 e $66 \%$, enquanto que outros nove ícones estavam muito baixo da taxa de compreensão, o que significa que há a necessidade que um projeto de redesign dos ícones seja realizado, sendo possível avaliar também que esses ícones, em sua maioria, faziam uma má relação entre o significado e o objeto real representado, bem como os ícones não estavam inseridos em um mesmo contexto de significado.

Percebeu-se também a importância de os ícones integrarem um inventário de signos coeso, integrando um sistema visual, com um ícone reforçando o sentido do outro. Para isso os ícones poderiam integrar uma mesma metáfora visual, como educação, ambiente de ensino, etc., desenvolvendo um campo semântico com um mesmo vocabulário visual e facilitando sua compreensão. 
Outra questão importante percebida pela pesquisa foi o aspecto cultural como fator de compreensão dos ícones. De maneira geral, os ícones não foram bem compreendidos pelos participantes cubanos, podendo deduzir que a nacionalidade é um fator determinante de compreensão de elementos visuais. Sobre isso Cardoso et al. (2014) comentam que a interpretação dos ícones é influenciada pelo contexto cultural, educacional e social e diferentes grupos podem ter diferentes expectativas. Assim, por se tratar de uma instituição que produz materiais que são classificados como Recursos Educacionais Abertos, seria interessante realizar um estudo com participantes de outros países na medida que a educação a distância rompe barreiras físicas, espaciais e nacionais.

Além disso, o uso de rótulos textuais, quando necessário (HIRATSUKA, 1996 apud CARDOSO et al., 2015), é um fator importante para a compreensão dos ícones, principalmente daqueles que apresentam semelhanças, como por exemplo o Livrotexto e o Livro multimídia (on-line).

No decorrer da pesquisa, observou-se a importância de saber de que forma um ícone é visto e se ele é compreendido, assim como a importância da utilização de símbolos gráficos para traduzir um conceito através de imagem, de forma mais rápida, o que interfere de forma direta a qualidade da interação e o desempenho do usuário e do sistema em si.

Como afirma Cardoso et al. (2013, p. 72): “E, a menos que o ícone esteja presente na interface meramente por motivos estéticos, será de grande importância que sua mensagem seja decodificada e com o menor esforço exigido". Logo, a escolha de utilizar metodologias de avaliação de compreensão para criar ou melhorar a implementação dos símbolos gráficos em qualquer sistema implica diretamente no seu êxito ou fracasso, chegando-se a conclusão de que para que serve um ícone que não é compreendido?

Por fim, sugere-se como continuidade para a pesquisa utilizar outros métodos de avaliação de ícones, como por exemplo o método de produção, bem como avaliar os ícones da perspectiva dos usuários cubanos, para então realizar o redesign dos ícones.

\section{REFERÊNCIAS}

BARROS, Vanessa Tavares de Oliveira. Avaliação da interface de um aplicativo computacional através de teste de usabilidade, questionário ergonômico e análise gráfica do design. Universidade Federal de Santa Catarina. 2003. Disponível em: <http://repositorio.ufsc.br/xmlui/handle/123456789/85542>. Acesso em: 23 abril 2015.

CARDOSO, Marina; GONÇALVES, Berenice; OLIVEIRA, Sandra. Avaliação de ícones para interface de um sistema médico on-line. Infodesign, São Paulo, v. 10, n.1, p.70-83, 2013.

CARDOSO, Marina Cascaes; GONÇALVES, Berenice Santos; OLIVEIRA, Sandra Regina Ramalho. Avaliação de ícones para interface de um sistema médico on-line. 6o

Congresso Internacional de Design da Informação - CIDI. São Paulo: Blucher, 2014. Disponível em: <http://www.proceedings.blucher.com.br/pdf/designproceedings/cidi//CIDI 114.pdf>. Acesso em: 08 abril 2015.

FORMIGA, Eliana. Símbolos gráficos: métodos de avaliação de compreensão: Contribuições à melhoria do projeto deste importante meio de comunicação visual de informações. São Paulo: Blucher, 2011. 148 p. 
FORMIGA, Eliana. MORAES, Anamaria de. Comparação de eficiência de métodos de avaliação de usabilidade pelo método binário. São Paulo, v. 9, n. 3, p. 143-152. 2012. Disponível em: <http://www.infodesign.org.br/infodesign/article/view/134/112>. Acesso em: 18 dez. 2014.

MOORE, Michael; KEARSLEY, Greg. Educação a Distância: uma Visão Integrada. São Paulo: Thomson Learning, 2007.

REIS, Guilhermo Almeida. Centrando a Arquitetura de Informação no Usuário. São Paulo. 2015. Disponível em:<http://www.teses.usp.br/teses/disponiveis/27/27151/tde23042007-141926/pt-br.php>. Acesso em: ago. 2015.

SANTANA, Bianca; ROSSINI, Carolina; PRETTO, Nelson de Lucca. Recursos

Educacionais Abertos: práticas colaborativas políticas públicas - 1. ed. Salvador: Edufba; São Paulo: Casa da Cultura Digital. 2012. 246 p. Disponível em: < http://www.livrorea.net.br/livro/livroREA-1edicao-mai2012.pdf>. Acesso em: 27 março2016. 